\title{
Immunoglobulins in the mouse uterus before implantation
}

\author{
O. Bernard, Flore Rachman and Dorothea Bennett* \\ Unité de Recherche d'Hépatologie Infantile, I.N.S.E.R.M. U 56, \& Clinique de Pédiatrie, \\ Université Paris-Sud, Hôpital d'Enfants, F-94270 Bicêtre, France and \\ * Memorial Sloan Kettering Cancer Center, New York, New York 10021, U.S.A.
}

\begin{abstract}
Summary. An indirect immunoperoxidase technique was used to study the distribution of $\operatorname{IgA}, \operatorname{IgG}, \operatorname{IgM}$ and albumin in the uterus of primigravid mice. As pregnancy proceeds from Days 2 to $6, \operatorname{IgA}$-containing plasma cells concentrate around the uterine glands, $\operatorname{IgA}$ is found in an increasing number of glands and then in the uterine lumen. At the same time the stroma is progressively invested by $\operatorname{IgG}$, but IgG plasma cells are not present in significant numbers and IgG is very rarely found in glands. IgM remains in blood vessels until Day 5 when it is present in small amounts in the stroma. Albumin tends to follow a pattern similar to that of IgG but in addition is present in the lumen and in a few cells in the luminal epithelium. The growing decidua does not contain immunoglobulin. These results suggest that, as the embryo reaches the uterine lumen, IgA, produced locally by plasma cells, is secreted into the uterine lumen via uterine glands while IgG infiltrates the stroma as a result of increased permeability of the uterine capillaries at the time of implantation.
\end{abstract}

\section{Introduction}

The mouse embryo is invested with maternal antibodies from the time of implantation (Bernard, Ripoche \& Bennett, 1977). It is not known, however, whether maternal immunoglobulins are present in the uterus or in the uterine lumen before implantation. An early interaction between the blastocyst and maternal immunoglobulins could be important both from conceptual (Bernard, 1977) and practical viewpoints with respect to peri-implantation immunological contraception (Billington, 1978). The present paper investigates the occurrence and distribution of immunoglobulins in the mouse uterus before implantation.

\section{Materials and Methods}

Random-bred albino female mice of the OF 1 strain and aged 8-10 weeks were mated with males of the same strain. The day a vaginal plug was found was considered Day 1 of pregnancy. The primigravid females were injected i.v. with $1 \%$ Pontamine blue $15 \mathrm{~min}$ before killing, by cervical dislocation, on Days 2, 3, 3.5, 4, 4.5, 5, 5.5 and 6. The presence of embryos in the oviduct and/or the uterus was checked except when a positive Pontamine blue reaction indicated actual implantation of the embryo (Days 5, 5.5 and 6). Uterine horns were fixed for $24 \mathrm{~h}$ in $4 \%$ paraformaldehyde and embedded in polyethyleneglycol 1000 as previously described (Bernard et al., 1977). Sections $(5 \mu \mathrm{m})$ were cut either longitudinally or transversely, and incubated for 30 $\min$ in $1: 20$ dilutions of rabbit antisera to mouse IgA, IgG or IgM (Litton Bionetics, Kensington, 
Maryland) or with rabbit antiserum to mouse albumin (Nordic Immunological Laboratories, Tilburg, Netherlands). Specificity of the sera was checked by immunodiffusion. After washing in

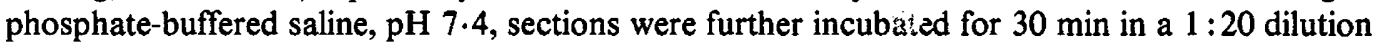
of peroxidase-labelled sheep Fab anti-rabbit immunoglobulin adsorbed on mouse immunoglobulin (kindly provided by Dr M. Lavergne, Institut Pasteur Productions, Paris). Following washing, sections were stained for $1 \mathrm{~min}$ in diaminobenzidine tetrahydrochloride (Fluka AG, Buchs, Switzerland; $50 \mathrm{mg}$ in $100 \mathrm{ml}$ Tris- $\mathrm{HCl}, \mathrm{pH} 7.6$ ) and $0.01 \% \mathrm{H}_{2} \mathrm{O}_{2}$. Immunoglobulin or albumin appears as a dark brown deposit. Sections were examined under phase-contrast microscopy or after haematoxylin counterstaining to study the morphology of the unstained areas.

The following controls were carried out. (1) Sections were incubated in PBS instead of antiserum and peroxidase conjugate in order to detect endogenous peroxidase activity. (2) Sections were incubated in normal rabbit serum instead of specific antiserum: this gave consistently negative results. (3) Sections were incubated with specific antisera and each of their corresponding antigens or unrelated antigens (purified mouse myeloma IgA, IgG and IgM from Bionetics Laboratories (Kensington, Maryland, U.S.A.); purified mouse albumin from Cappel Laboratories (Downington, Pennsylvania, U.S.A.)) instead of the specific antisera alone. Co-incubation of anti-immunoglobulin antisera with their corresponding antigens (e.g. rabbit anti-mouse IgA with purified mouse $\operatorname{IgA}$ ) suppressed staining. Co-incubation of anti-albumin with albumin significantly reduced the intensity of staining. Staining was not altered by co-incubation of the antisera with unrelated antigens (e.g. rabbit anti-mouse IgA with purified IgG, IgM or albumin). (4) Standard positive controls for each immunoglobulin antiserum were obtained on sections of mouse iliac lymph nodes.

\section{Results}

On Day 2 of pregnancy, IgA-containing plasma cells were present in moderate amounts around the uterine glands in the antimesometrial area and the stroma was virtually devoid of any immunoglobulin except for a very small amount of IgG in a few sections. Blood vessels contained $\operatorname{IgG}$ and to a lesser extent $\operatorname{IgM}$ and $\operatorname{IgA}$. Most uterine glands did not contain immunoglobulin; there was a thin lining of $\operatorname{IgA}$ and $\operatorname{IgG}$ on the apices of the epithelial cells in a few. Albumin was found in blood vessels and sometimes in moderate amounts in the stroma.

During Day 3 a growing number of IgA plasma cells were visible in the stroma, chiefly around the glands (Pl. 1, Fig. 1). Late on Day 3 a limited (about 15-20\%) number of gland lumina in the antimesometrial area contained a moderate amount of IgA, and IgA was occasionally seen within the glandular epithelium. The stroma did not contain any IgG early on Day 3 (Pl. 1, Fig. 2), except for a very limited number of IgG plasma cells, but IgG was detectable by Day 3.5 in increasing amounts in the stroma, mostly in areas where the capillaries and blood vessels were proliferating. Occasionally one or two glands contained a very faint staining for IgG, and the number of IgG plasma cells remained very low. Albumin was also present in the stroma but was not seen in glands. IgM remained in the blood vessels.

On Day 4 IgA plasma cells were very abundant in the stroma and $40-80 \%$ of gland lumina contained IgA, sometimes within the epithelium. IgG was visible throughout the stroma, although the intensity of the staining was uneven along the uterine horn, being most conspicuous where vascular and glandular proliferation was maximal. In most sections, glands did not contain IgG, and, when present, it was seen as a very faint staining in less than $15 \%$ of glands in a section. IgG plasma cells were detectable only occasionally. IgM still remained in the vessels while some free $\operatorname{IgA}$ was seen in the stroma, although only in the areas where IgG concentrations were highest. Albumin was present in large amounts throughout the stroma but was present in $<20 \%$ of glands and then only faintly. However, a few luminal epithelium cells contained albumin. 

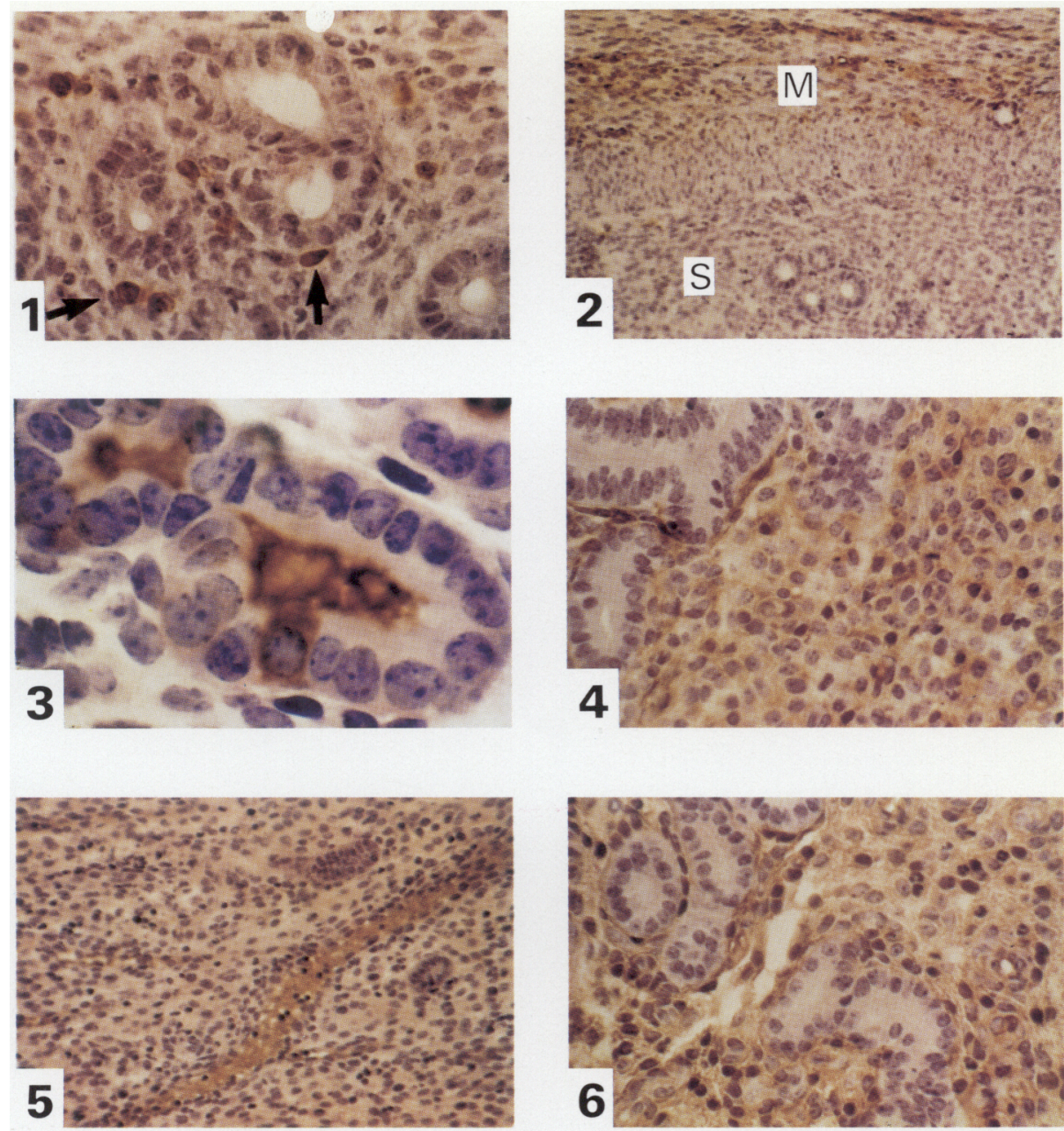

Figs 1 and 2. Mouse uterus on Day 3 of pregnancy showing IgA plasma cells (arrows) around the glands (Fig. 1, $\times 230$ ) and $\operatorname{IgG}$ in the myometrium $(\mathrm{M})$ but not in the stroma (S) (Fig. 2, $\times 81$ ).

Figs 3-6. Mouse uterus at Day 5 of pregnancy.

Fig. 3. $\operatorname{Ig} \mathrm{A}$ is present in the gland lumen and in a glandular epithelial cell. $\times 633$.

Fig. 4. $\mathrm{IgG}$ is present in the stroma but not in the glands. $\times 200$.

Fig. 5. IgM is present in blood vessels but not in the stroma. $\times 100$.

Fig. 6. Albumin is present in the stroma but not in the glands. $\times 200$.

(Facing p. 238) 
On Day 5 IgA plasma cells were present in amounts similar to those on Day 4, and over $70 \%$ of glands contained IgA (Pl. 1, Fig. 3). IgG infiltration of the stroma was massive (Pl. 1, Fig. 4), underlining the basement membranes of glands and luminal epithelium, but fewer than $10 \%$ of glands contained IgG and always very faintly. IgG plasma cells remained sparse. IgG staining was still most prominent where vascular proliferation was great, but was much fainter and sometimes absent in other areas where cells were more densely packed, presumably the primary decidual zone (Finn \& McLaren, 1967). IgM remained mostly in vessels (Pl. 1, Fig. 5), but some IgM and IgA were present in the stroma where vascular proliferation was extensive. IgM was not found in glands. Albumin had a stromal distribution similar to that of IgG (P1. 1, Fig. 6); it was not found in the glands but was present in several cells of the luminal epithelium. The luminal fluid stained for albumin at this stage.

The early decidua was clearly devoid of any immunoglobulin or albumin on Days 5.5 and 6, except in the small capillaries. IgA plasma cells, IgA-containing glands and massive IgG and albumin infiltration of the stroma were found, along with some free $\operatorname{IgA}$ and $\operatorname{IgM}$, but only at the periphery of the implantation sites. $\operatorname{IgA}$ and albumin were present in the uterine fluid on Day 6 and some discrete granules of albumin were visible in the apical regions in several cells of the luminal epithelium. Within the implantation site the embryo contained $\operatorname{IgG}$ and albumin as discrete granules in the trophoblast and early endoderm.

\section{Discussion}

As in the gut, bronchus and mammary gland (McDermott \& Bienenstock, 1979), uterine IgA plasma cells are probably the source of the $\operatorname{IgA}$ found in the glands and uterine lumen in the mouse at the time of implantation. Dimeric IgA secreted locally by plasma cells presumably binds to secretory components on the epithelial cells (Tourville, Ogra, Lippes \& Tomasi, 1970) and then is carried to the gland lumen. Ultrastructural features of secretory activity have been described for mouse uterine glands during delayed implantation (Given \& Enders, 1978) and $\mathrm{IgA}$ is known to cross the glandular epithelium in the human uterus during the secretory phase of the cycle (Kelly \& Fox, 1979). In contrast to IgA and albumin, IgG does not seem to be significantly secreted in the glands or through the luminal epithelium at this time. Stromal IgG probably originates directly in the blood vessels, and accumulates in the tissue because of increased permeability of capillaries at the time of implantation (Psychoyos, 1960). The same increase in vascular permeability probably accounts for the smaller amount of free IgM and IgA found in the stroma.

IgA plasma cell infiltration, secretion of $\operatorname{IgA}$ in the glands and $\operatorname{IgG}$ diffusion in the stroma are all likely to be under hormonal control. IgA B cells from mesenteric lymph nodes migrate to mammary glands at the end of pregnancy and during lactation (Roux, MacWilliams, Phillips-Quagliata, Weisz-Carrington \& Lamm, 1977) and the oestradiol surge at pro-oestrus is known to induce secretion of $\operatorname{IgA}$ and IgG into rat uterine fluid (Wira \& Sandoe, 1977). However, our results show that in the preimplantation period in the mouse, IgG does not seem to be secreted into the uterine fluid; this difference may reflect the modulation by progesterone of oestradiol activity (Hsueh, Peck \& Clark, 1975; Fishel, 1979) and/or the smaller levels of oestradiol secreted on Day 4 of pregnancy as compared with the pro-oestrous surge (McCormack \& Greenwald, 1974).

The presence of IgG and albumin in the early implanted blastocyst confirms earlier findings (Bernard et al., 1977) and correlates well with the presence of binding sites for IgG and albumin on mouse blastocysts activated for implantation (Håkansson \& Sundqvist, 1976). Since neither albumin nor IgG is detected in the early decidua it can be suggested that albumin binds to the embryo while it is still in the lumen, and that $\operatorname{IgG}$ is probably taken up by the embryo from the capillaries under the epithelium and later in the decidua. 
Uterine IgA secretion at the time of implantation may have several meanings. It may simply be part of the proteins of uterine or serum origin secreted at this time (Gore-Langton \& Surani, 1976) to nourish or activate the blastocyst for implantation. However, secreted IgA may play a role relevant to the immunological balance of pregnancy. $\operatorname{IgA}$ is in fact detected in the apices of the luminal epithelial cells on Day 7 (Bernard et al., 1977; O. Bernard, unpublished observations), suggesting that it is reabsorbed from the luminal fluid by the epithelium, possibly after interaction with embryonic antigens. Further search for specific antibodies able to interact with embryonic antigens in the immediate preimplantation period should therefore perhaps focus on the locally produced IgA rather than systemic immunoglobulins.

This work was supported by DGRST BRD P 577, INSERM CRL 78-5-022-4, UER Kremlin-Bicêtre 743 and USPHS grants CA08748 and HD10668.

\section{References}

Bernard, O. (1977) Possible protecting role of maternal immunoglobulins on embryonic development in mammals. Immunogenetics 5, 1-15.

Bernard, O., Ripoche, M.A. \& Bennett, D. (1977) Distribution of maternal immunoglobulins in the mouse uterus and embryo in the days after implantation. J.exp. Med. 145, 58-75.

Billington, W.D. (1978) Immunological interference with implantation. Uppsala J. Med. Sci., Suppl. 22, $51-58$.

Finn, C. A. \& McLaren, A. (1967) A study of the early stages of implantation in mice. J. Reprod. Fert. 13, 259-267.

Fishel, S.B. (1979) Analysis of mouse uterine proteins at pro-oestrus, during early pregnancy and after administration of exogenous steroids. J. Reprod. Fert. 55, $91-100$.

Given, R.L. \& Enders, A.C. (1978) Mouse uterine glands during the delayed and induced implantation periods. Anat. Rec. 190, 271-284.

Gore-Langton, R.E. \& Surani, M.A.H. (1976) Uterine luminal proteins of mice. J. Reprod. Fert. 46, 271-274.

Häkansson, S. \& Sundqvist, K.G. (1976) Binding of proteins to mouse blastocysts after the attachment stage of implantation. Uppsala J. Med. Sci. 81, 139-144.

Hsueh, A.J.W., Peck, E.J. \& Clark, J.H. (1975) Progesterone antagonism of the oestrogen receptor and oestrogen-induced uterine growth. Nature, Lond. 254, 337-339.
Kelly, J.K. \& Fox, H. (1979) The local immunological defence system of the human endometrium. $J$. Reprod. Immunol. 1, 39-45.

McCormack, J.T. \& Greenwald, G.S. (1974) Progesterone and oestradiol-17 $\beta$ concentrations in the peripheral plasma during pregnancy in the mouse. $J$. Endocr. 62, 101-107.

McDermott, M.R. \& Bienenstock, J. (1979) Evidence for a common mucosal immunologic system. I. Migration of B immunoblasts into intestinal, respiratory, and genital tissues. J. Immunol. 122, 1892-1898.

Psychoyos, A. (1960) La réaction déciduale est précédée de modifications précoces de la perméabilité capillaire de l'utérus. C. r. Séanc. Soc. Biol. 154, 1384-1387.

Roux, M.E., MacWilliams, M., Phillips-Quagliata, J.M., Weisz-Carrington, P. \& Lamm, M.E. (1977) Origin of IgA-secreting plasma cells in the mammary gland. J. exp. Med. 146, 1311-1322.

Tourville, D.R., Ogra, S.S., Lippes, J. \& Tomasi, T.B. (1970) The human female reproductive tract: immunohistological localization of $\gamma \mathrm{A}, \gamma \mathrm{G}, \gamma \mathrm{M}$, secretory "piece", and lactoferrin. Am. J. Obstet. Gynec. 108, 1102-1108.

Wira, C.R. \& Sandoe, C.P. (1977) Sex steroid hormone regulation of $\mathrm{IgA}$ and $\mathrm{IgG}$ in rat uterine secretions. Nature, Lond. 268, 534-536. 